\title{
Circuit
}

Musiques contemporaines

\section{Les illustrations du numéro}

\section{Michel Butor}

Volume 12, numéro 1, 2001

Henri Pousseur : visages

URI : https://id.erudit.org/iderudit/902245ar

DOI : https://doi.org/10.7202/902245ar

Aller au sommaire du numéro

Éditeur(s)

Les Presses de l'Université de Montréal

ISSN

1183-1693 (imprimé)

1488-9692 (numérique)

Découvrir la revue

Citer ce document

(2001). Les illustrations du numéro : Michel Butor. Circuit, 12(1), 103-104.

https://doi.org/10.7202/902245ar

Ce document est protégé par la loi sur le droit d'auteur. L'utilisation des services d'Érudit (y compris la reproduction) est assujettie à sa politique d'utilisation que vous pouvez consulter en ligne.

https://apropos.erudit.org/fr/usagers/politique-dutilisation/
Cet article est diffusé et préservé par Érudit.

Érudit est un consortium interuniversitaire sans but lucratif composé de l'Université de Montréal, l'Université Laval et l'Université du Québec à Montréal. Il a pour mission la promotion et la valorisation de la recherche. https://www.erudit.org/fr/ 


\section{LES ILLUSTRATIONS DU NUMÉRO}

\section{Michel Butor}

Michel Butor est né en 1926, en banlieue de Lille. Après des études de lettres et philosophie, tout en servant de secrétaire à Jean Wahl pour le Collège de philosophie (ce qui lui permet de se frotter à maints intellectuels d'alors), il enseigne quelques mois au lycée Mallarmé à Sens. Profitant d'un essai de réforme de l'enseignement égyptien, il traverse la Méditerranée et se retrouve professeur dans la vallée du Nil. Puis il saisit une occasion de devenir lecteur à l'université de Manchester en Angleterre.

Possédé depuis longtemps par le démon de l'écriture, il publie ses premiers romans aux Éditions de Minuit. Prix littéraires, travail chez des éditeurs, un peu de vie parisienne, conférences ici et là, nombreux voyages aux États-Unis. Après mai 68, au retour d'une année au Far-West, il tente une rentrée dans l'enseignement universitaire français puis est nommé professeur à la faculté des lettres de Genève. Les livres s'accumulent, apportant chaque fois la surprise : essais, récits du jour ou de la nuit, poèmes, nouvelles combinaisons de tout cela, ils font le désespoir des esprits routiniers ; les collaborations se multiplient avec peintres, musiciens, photographes. II séjourne au Japon et en Australie, voyage en Chine. Retraité depuis 1991, il vit désormais dans un village de Haute-Savoie, tout en continuant à courir le monde.

\section{Bibliographie (extraits) :}

L'emploi du temps, roman, Éditions de Minuit, 1956.

Mobile, études pour une représentation des États-Unis, Gallimard, 1962.

Répertoire, 5 volumes, essais et conférences, Éditions de Minuit, 1960-1982.

Le génie du lieu, 5 volumes, critique géographique, Grasset, 1958, puis

Gallimard: Où, 1971, Boomerang, 1978, Transit, 1992, Gyroscope, 1996.

Dialogue avec trente-trois variations sur une valse de Diabelli, Gallimard, 1971. 
Matière de rêves, 5 volumes, onirographie, Gallimard, 1975-1985.

Improvisations, 7 volumes, enseignement universitaire, la Différence, sur Flaubert, 1984, Michaux, 1985 (repris en 1999 sous le titre Le sismographe aventureux).

Rimbaud, 1989, Butor, 1993, Balzac, 13 volumes: Le marchand et le génie, Paris à vol d'archange, Scènes de la vie fémininel, 1998.

À la frontière, poésie, la Différence, 1996.

\section{Les œuvres}

Les illustrations de ce numéro sont nées de l'amitié qui unit Michel Butor et Henri Pousseur. Outils de communication, ces cartes postales sont des œuvres qui se constituent au fil des ajouts de l'un des deux correspondants.

Elles sont en fait, pour certaines, des œuvres à deux. Ainsi, une partie des collages des pages 8 et 18 (dont les pages 17 et 28 constituent respectivement une version déployée où la correspondance peut se lirel est constituée d'ajouts postérieurs d'Henri Pousseur sur une base de Michel Butor.

- p. 44, photographie de Michel Colignon, avec texte de Michel Butor pour le livre L'Aisselle de la forêt. Photographie reprise comme fond pour les collages des pages 18 et 28 .

- p. 8 et 17, collage à partir d'un portrait de Michel Butor (octobre 1999) par Maxime Godard.

- p. 18, 28, 72 et 86, utilisation d'une photographie de Michel Colignon, extraite du livre L'Humus Inscrit avec texte de Michel Butor. 